\title{
Bacterial magnetosomes: microbiology, biomineralization and biotechnological applications
}

\author{
D. Schüler · R. B. Frankel \\ Max-Planck-Institut für Marine Mikrobiologie, 28359 Bremen, Germany \\ Department of Physics, California Polytechnic State University, San Luis Obispo, CA 93407, USA
}

\begin{abstract}
Magnetotactic bacteria orient and migrate along geomagnetic field lines. This ability is based on intracellular magnetic structures, the magnetosomes, which comprise nanometer-sized, membrane-bound crystals of the magnetic iron minerals magnetite $\left(\mathrm{Fe}_{3} \mathrm{O}_{4}\right)$ or greigite $\left(\mathrm{Fe}_{3} \mathrm{~S}_{4}\right)$. Magnetosome formation is achieved by a mineralization process with biological control over the accumulation of iron and the deposition of the mineral particle with specific size and orientation within a membrane vesicle at specific locations in the cell. This review focuses on the current knowledge about magnetotactic bacteria and will outline aspects of the physiology and molecular biology of the biomineralization process. Potential biotechnological applications of magnetotactic bacteria and their magnetosomes as well as perspectives for further research are discussed.
\end{abstract}

\section{Introduction}

The formation of biological hard materials, i.e., bone, shell and spicule, involves the deposition of specific inorganic minerals on or in an organic matrix in a highly controlled manner (Lowenstam 1981). Much current research is directed towards understanding these biomineralization processes, which are collectively known as biologically controlled mineralization, because of their relevance to the synthesis of advanced materials with tailored properties (Mann 1993; Moskowitz 1995).

One of the most intriguing examples of biologically controlled mineralization is the formation of magnetic nano-crystals in magnetosomes within magnetotactic bacteria. The formation of magnetosomes in these organisms is a well-documented example of the apparently widespread occurrence of magnetic minerals in the living world. Biomineralization of ferromagnetic materials, mainly magnetite, has been reported for an extremely diverse range of organisms including algae (Torres de Araujo et al. 1986), insects (Maher 1998), molluscs (Lowenstam 1981), fish (Mann et al. 1988), birds (Wiltschko and Wiltschko 1995) and even humans (Kirschvink et al. 1992). The discovery of magnetotactic bacteria by R. Blakemore (1975) stimulated interdisciplinary research interest among scientists, including microbiologists, physicists, geologists, chemists, and engineers. Commercial uses of bacterial magnetosome particles have been suggested, including the manufacture of magnetic tapes and printing inks, magnetic targeting of pharmaceuticals, cell separation and their application as contrast-enhancement agents in magnetic resonance imaging (Blakemore 1983; Mann et al. 1990; Matsunaga 1991; Schwartz and Blakemore 1984).

\section{Ecology and phylogeny of magnetotactic bacteria}

Magnetotactic bacteria represent a heterogeneous group of procaryotes with a variety of morphological types including cocci, rods, vibrios, spirilla and apparently multicellular forms (Bazylinski et al. 1994; Spring and Schleifer 1995). They are constituents of natural microbial communities in sediments and chemically stratified water columns and a broad diversity of morphological forms has been found in many marine and freshwater habitats. The highest numbers of magnetotactic bacteria are generally found at the oxic/anoxic transition zone or redoxocline, which is located in many freshwater habitats at the sediment/water interface or just below (Bazylinski 1995; Stolz 1993). Accordingly, nearly all of 
the cultivated bacteria exhibit a strong preference for low oxygen concentrations and behave as typical microaerophiles. In some environments, magnetotactic bacteria have been shown to be the dominant species of the bacterial population (Spring et al. 1993), implying a significant ecological role for these organisms.

Examinations of natural communities by molecular phylogenetic techniques have revealed a considerable phylogenetic diversity of natural populations of magnetotactic bacteria. The vast majority of magnetotactic bacteria, including cocci and rods, as well as all cultivable vibrios and spirilla, are members of the $\alpha$-Proteobacteria. A morphologically distinct, large magnetic rod was assigned to the Nitrospira phylum, whereas a "multicellular magnetic procaryote" and a magnetic sulfate-reducing bacterium were found to belong to the $\delta$ subclass of Proteobacteria (DeLong et al. 1993; Spring and Schleifer 1995).

\section{Isolation and axenic cultivation}

Their directed migration in magnetic fields can easily be used to enrich magnetotactic bacteria and collect them from natural samples in significant numbers. However, despite their ubiquitous occurrence and high abundance, cultivation of magnetotactic bacteria in the laboratory has proven difficult to achieve and only a small minority of the broad spectrum of naturally occurring magnetotactic bacteria have been isolated in pure culture. Difficulties in isolating and cultivating of magnetotactic bacteria arise from their lifestyle, which is adapted to sediments and chemically stratified aquatic habitats. As typical gradient organisms, magnetotactic bacteria appear to depend on a complex pattern of vertical chemical and redox gradients, which are difficult to mimic under laboratory conditions. Examples of isolates that can be grown under laboratory conditions include several strains of Magnetospirillum (Fig. 1; Blakemore et al. 1979; Burgess et al. 1993; Schleifer et al. 1991; Schüler and Köhler 1992). Two strains of a marine magnetic vibrio were isolated that can be grown either anaerobically or microaerobically (Bazylinski et al. 1988; Meldrum et al. 1993a). The only cultivable magnetic coccus was grown microaerobically in gradient cultures (Meldrum et al. 1993b). Sakaguchi et al. (1993) were the first to isolate an obligate anaerobic, sulfate-reducing magnetotactic bacterium.

\section{Magnetotaxis}

A widely accepted hypothesis about the function of magnetotaxis is that, because all known magnetotactic bacteria are either microaerophilic or anaerobic, they seek to avoid high oxygen levels and their navigation along the geomagnetic field lines facilitates migration to their favored position in the oxygen gradient (Frankel and Bazylinski 1994). The preferred motility direction found in natural populations of magnetotactic bacteria is northward in the geomagnetic field in the northern hemisphere, whereas it is southward in the southern hemisphere. Because of the inclination of the geomagnetic field, migration in these preferred directions would cause cells in both hemispheres to swim downward. Recent findings indicate that this process is complex and involves interactions with an aerotactic sensory mechanism (Frankel et al. 1997, 1998). Besides magnetotaxis, other possible functions of intracellular iron deposition have been discussed, including iron homeostasis, energy conservation, or redox cycling (Mann et al. 1990; Guerin and Blakemore 1992; Spring et al. 1993). This might explain the large numbers of magnetic crystals in some bacteria.

Fig. 1 Electron micrograph of a Magnetospirillum gryphiswaldense cell exhibiting the characteristic morphology of magnetic spirilla. The helical cells are bipolarly flagellated and contain up to 60 intracellular magnetite particles in magnetosomes, which are arranged in a chain. (Bar equivalent to $0.5 \mu \mathrm{m}$ )

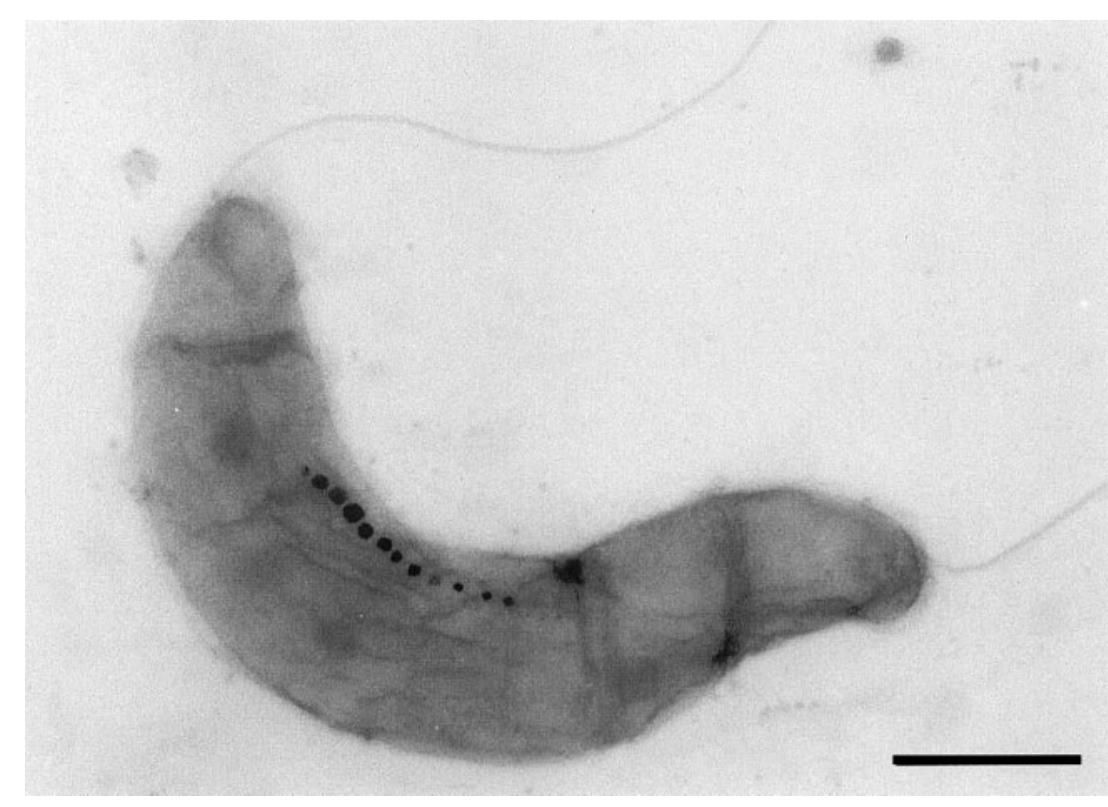




\section{Magnetosomes}

The inorganic phase: magnetic minerals

Magnetosomes are found in all magnetotactic bacteria and consist of magnetic iron mineral particles enclosed within membrane vesicles. In most cases the magnetosomes are organized in a chain or chains, which are apparently fixed within the cell. In many magnetotactic bacterial strains the iron mineral particles consist of
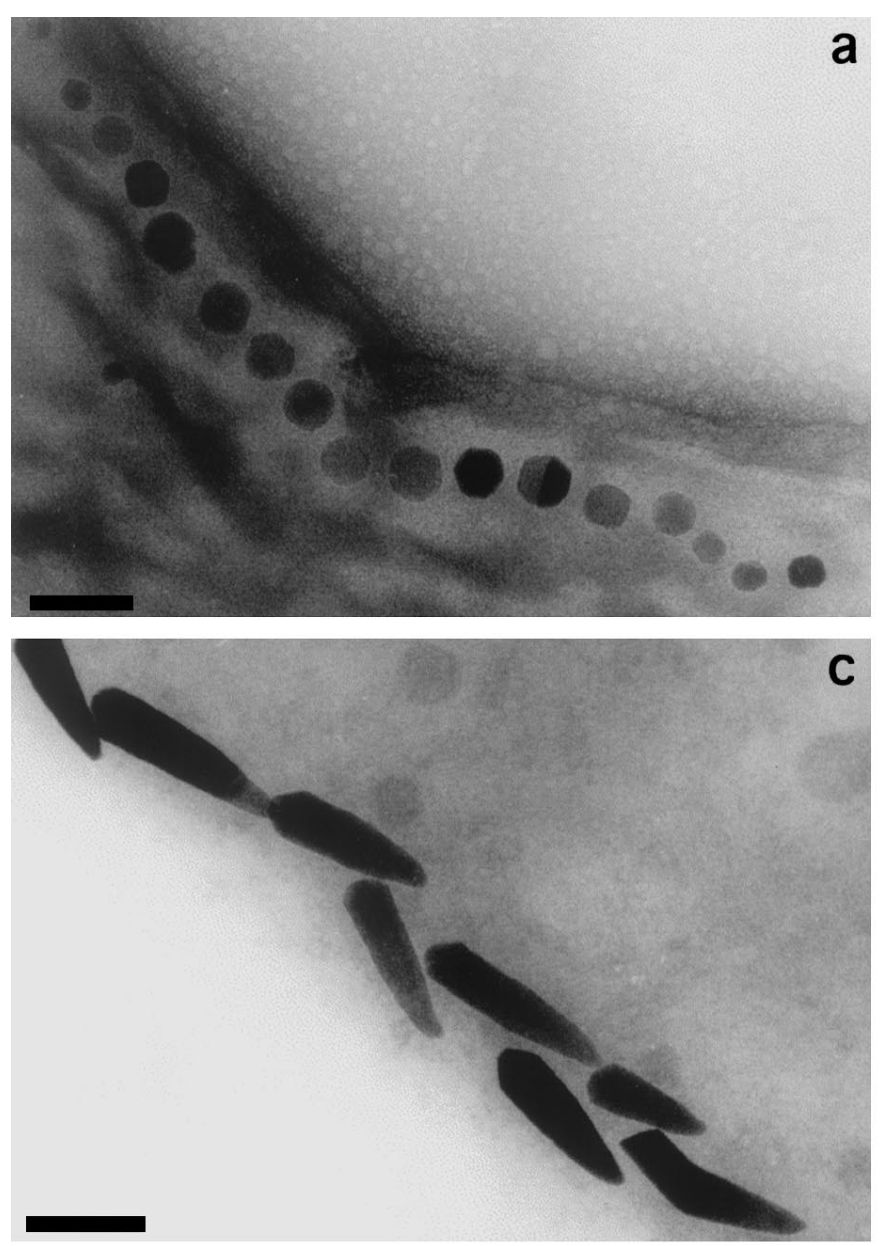

e

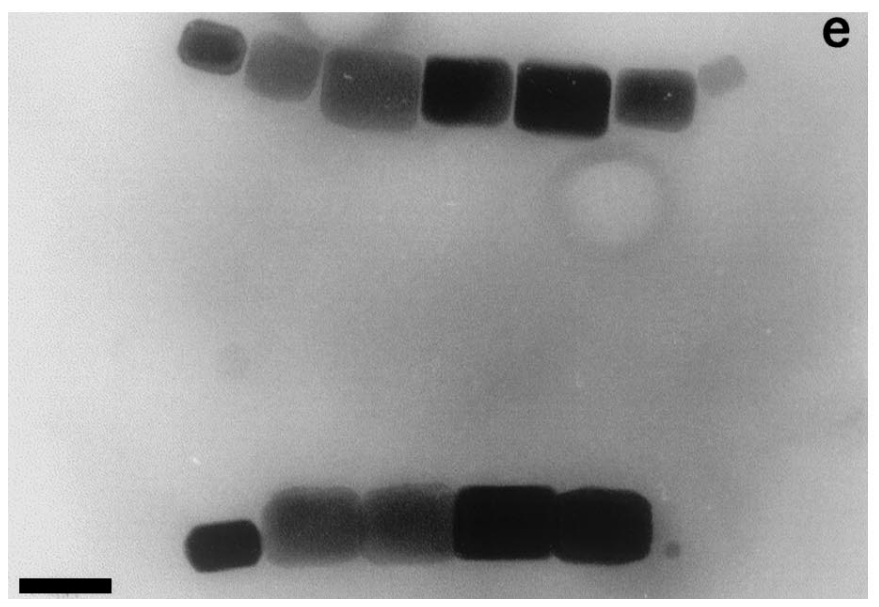

magnetite, $\mathrm{Fe}_{3} \mathrm{O}_{4}$, and are characterized by narrow size distributions and uniform, species-specific crystal habits (Fig. 2). The crystal habits all consist of various combinations of the isometric forms $\{111\},\{110\}$ and $\{100\}$.

Fig. 2a-f Electron micrographs of crystal morphologies and intracellular organization of magnetosomes found in various magnetotactic bacteria. Shapes of magnetic crystals include cubo-octahedral (a), elongated hexagonal prismatic (b, d, e, f) and bullet-shaped morphologies (c). The particles are arranged in one $(\mathbf{a}, \mathbf{b}, \mathbf{c})$, two (e) or multiple chains (d) or irregularly (f). (Bar equivalent to $100 \mathrm{~nm}$ )
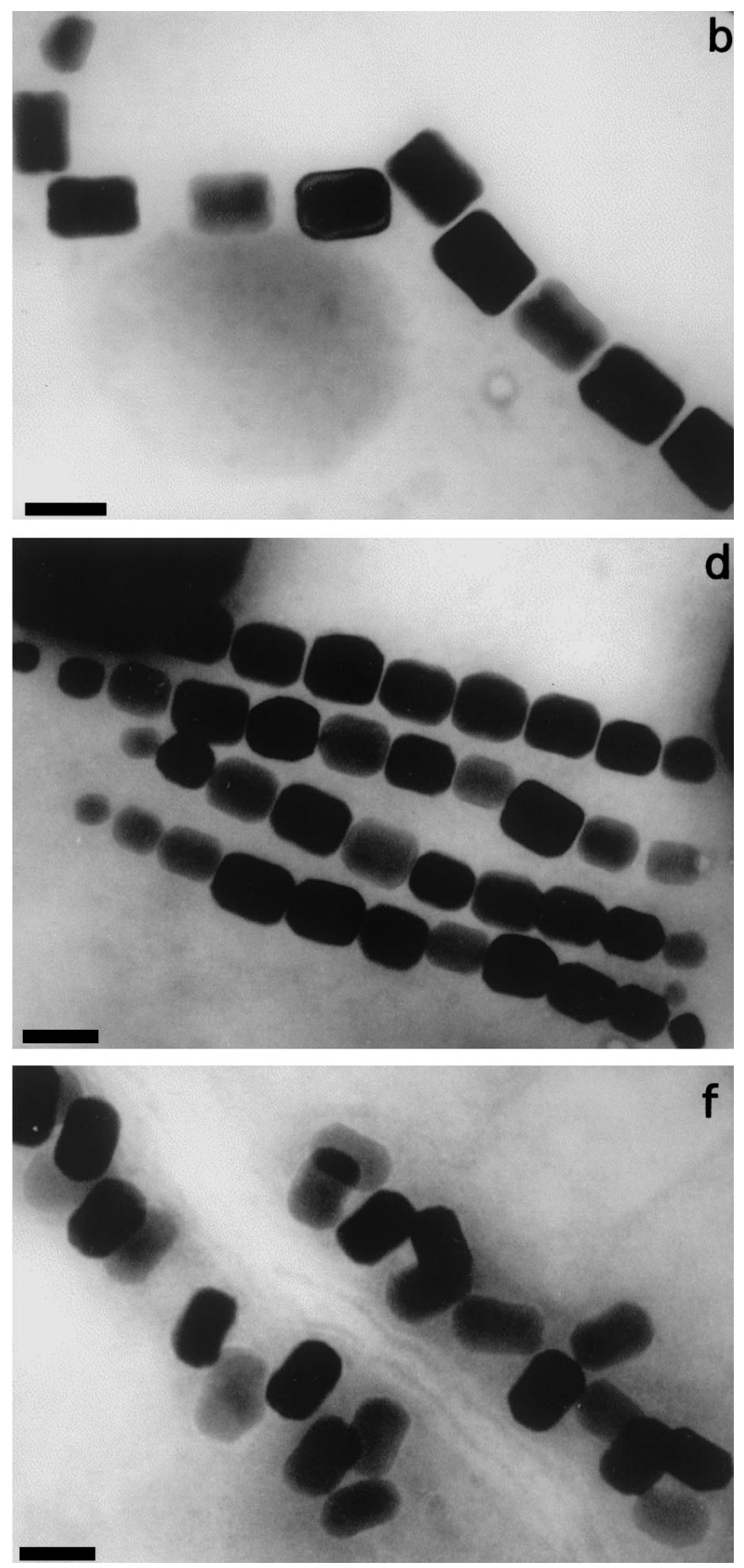
The particles are oriented with a [ 1111$]$ crystal axis along the chain direction. The particle sizes are typically 35$120 \mathrm{~nm}$, which is within the permanent, single-magneticdomain-size range for magnetite (Moskowitz 1995).

In several magnetotactic bacteria from marine, sulfidic environments, the magnetosome particles consist of the iron-sulfide mineral greigite, $\mathrm{Fe}_{3} \mathrm{~S}_{4}$, which is isostructural with magnetite and is also ferrimagnetically ordered. Greigite magnetosomes are also characterized by narrow size distributions and species-specific crystal habits, but are oriented with a [ 100$]$ crystal axis along the chain direction. Non-magnetic mackinawite, FeS, has been found in cells with greigite magnetosomes and is thought to be a precursor to greigite mineralization (Posfai et al. 1998).

It should be noted that metabolic activities of dissimilatory iron-reducing bacteria (Lovley et al. 1987) and sulfate-reducing bacteria can result in the formation of extracellular magnetite and greigite respectively, by processes known as biologically induced mineralization. However, unlike the mineral particles in the magnetotactic bacteria, biologically induced mineralization is not controlled by the organism and is characterized by $\log /$ normal size distributions and non-unique crystal habits (Sparks et al. 1990).

When magnetosomes are arranged in a single chain, as in Magnetospirillum species, magnetostatic interactions between the single-magnetic domain particles cause the particle magnetic moments to orient spontaneously parallel to each other along the chain direction (Frankel and Blakemore 1980). This results in a permanent magnetic dipole associated with the chain with a natural remanent magnetization approaching the saturation magnetization (Dunin-Borkowski et al. 1998) and sufficiently large to be oriented along the geomagnetic field at ambient temperature. Since the chain of particles is fixed within the cell, the entire cell will be oriented in the field. This passive orientation results in the migration of the cell along the magnetic field lines as it swims. Thus the bacteria have elegantly solved the problem of how to construct a magnetic dipole that will be oriented in the geomagnetic field yet fit inside a micrometer-sized cell. The solution is based on the ability of the bacteria to control the mineral type of the iron, the size and orientation of the particles, and their placement in the cell.

The organic phase: the magnetosome membrane

In all magnetite-producing magnetotactic bacteria examined to date, the magnetosome mineral phase appears to be enveloped by a membrane (Fig. 3; Gorby et al. 1988; Matsunga 1991; Schüler and Baeuerlein 1997b). Although the magnetosome membrane does not appear to be contiguous with the cell membrane in electronmicroscopic images, it can be speculated that some sort of connection or association with the cytoplasmic membrane exists. This would help explain the biosynthetic origin of the magnetosome compartment. A membranous "superstructure" may also account for the integrity of complex intracellular arrangements of magnetosome particles found in some magnetotactic bacteria. Empty and partially filled vesicles have been observed in iron-starved cells of M. magnetotacticum and M. gryphiswaldense (Gorby et al. 1988; Schüler and Baeuerlein 1997b), so it seems likely that the magnetosome membrane pre-exists as an "empty" vesicle prior to the biomineralization of the mineral phase.

In strains of Magnetospirillum, the magnetosome membrane was found to consist of a bilayer containing phospholipids and proteins, at least several of which appear unique to this membrane (Gorby et al. 1988; Schüler and Baeuerlein 1997b). Although the protein patterns of the magnetosome membrane are distinguishable between different strains of Magnetospirillum, at least one major protein with a molecular weight of about $22-24 \mathrm{kDa}$ appears to be common to all strains tested so far, as revealed by sequence analysis and
Fig. 3 Magnetosome particles isolated from M. gryphiswaldense. The magnetite crystals are typically $42 \mathrm{~nm}$ in diameter and are surrounded by the magnetosome membrane (arrow). (Bar equivalent to $25 \mathrm{~nm})$

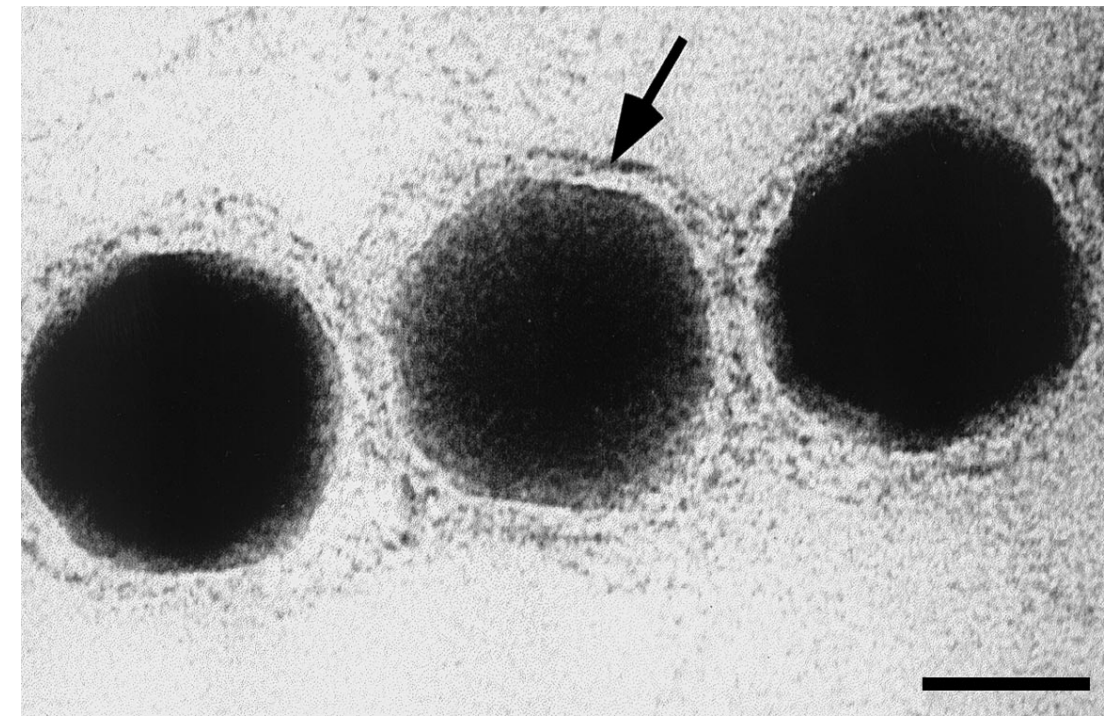


antibody cross-reactivity (Okuda et al. 1996; Schüler et al. 1997).

Compartmentalization through the formation of the magnetosome vesicle enables the processes of mineral formation to be regulated by biochemical pathways. The membrane may act as a potential gate for compositional, $\mathrm{pH}$ and redox differentiation between the vesicle and the cellular environment. Although the exact role of the magnetosome-specific proteins has not been elucidated, it has been speculated that these have specific functions in the accumulation of iron, nucleation of minerals and redox and pH control (Gorby et al. 1988; Mann et al. 1990).

\section{Physiology and biochemistry of bacterial magnetite biomineralization}

The first step in magnetite synthesis in magnetotactic bacteria is the uptake of iron. Because of the large amounts of iron required for magnetite synthesis, magnetotactic bacteria can be expected to use very efficient uptake systems. The assimilation of iron must be strictly controlled because of the potentially harmful effects of excess intracellular iron (Guerinot 1994). Several studies, all involving magnetic spirilla, have focused on iron uptake. Paoletti and Blakemore (1986) reported the production of a hydroxamate-type siderophore if cells of M. magnetotacticum were grown under conditions of high iron. However, these results have not been replicated in other studies and no conclusive evidence for the involvement of siderophores in the formation of magnetite has been found so far. Nakamura et al. (1993b) hypothesized that ferric iron was taken up in Magnetospirillum AMB-1 by a periplasmic binding-proteindependent iron-transport system. In M. gryphiswaldense, it was found that the major portion of the iron is taken up as $\mathrm{Fe}(\mathrm{III})$ in an energy-dependent process (Schüler and Baeuerlein 1996). The observed high rates of ferric iron uptake may reflect the extraordinary requirement for iron in these organisms. Both the amount of magnetite formed and the rate of ferric iron uptake were close to saturation at extracellular iron concentrations of $15-20 \mu \mathrm{M} \mathrm{Fe}$, indicating that this bacterium is able to accumulate copious amounts of iron from relatively low environmental concentrations.

The biomineralization of magnetic crystals does not occur constitutively, but largely depends on the growth conditions. Besides the availability of micromolar amounts of iron, microaerobic conditions are required for magnetite formation in Magnetospirillum species (Blakemore et al. 1985; Schüler and Baeuerlein 1998). Cells of $M$. gryphiswaldense are non-magnetic during aerobic growth, but start to produce $\mathrm{Fe}_{3} \mathrm{O}_{4}$ immediately after the establishment of microaerobic conditions corresponding to an oxygen concentration of about $1 \%-$ $3 \%$ saturation (Fig. 4). The accumulation of iron during growth is apparently tightly coupled to the induction of magnetite biomineralization. While the intracellular iron

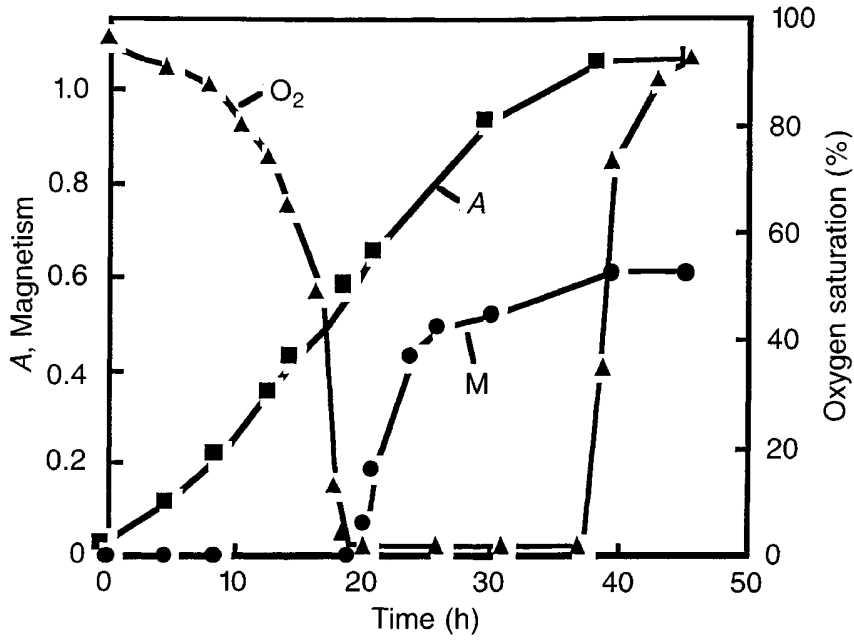

Fig. 4 Growth $(A)$, magnetism $(M)$, and dissolved oxygen concentration $\left(\mathrm{O}_{2}\right)$ in a culture of $M$. gryphiswaldense at constant aeration. Changes in magnetism of the cell suspension were monitored by measurement of differential light scattering (Schüler et al. 1995); growth was measured by absorbance. The cells were non-magnetic during aerobic growth. After $20 \mathrm{~h}$ the production of $\mathrm{Fe}_{3} \mathrm{O}_{4}$ was induced by the establishment of microaerobic conditions, corresponding to an oxygen concentration of about $1 \%-3 \%$ saturation

content in non-magnetic cells is relatively low, magnetic cells can contain more then $2 \%$ iron on a dry-weight base (Schüler and Baeuerlein 1998).

In an effort to elucidate the relationship between respiratory electron transport in nitrate and oxygen utilization and magnetite synthesis, cytochromes in M. magnetotacticum have been examined. Tamegai et al. (1993) reported a novel "cytochrome-a ${ }_{1}$-like" hemoprotein that was in greater amounts in magnetic cells than in nonmagnetic cells. A new $c c b$-type cytochrome $c$ oxidase (Tamegai and Fukumori 1994) and a cytochrome $c d_{1}$-type nitrite reductase (Yamazaki et al. 1995) were isolated and purified from M. magnetotacticum. The latter protein is of particular interest since it showed $\mathrm{Fe}(\mathrm{II})$ :nitrite oxidoreductase activity. It has also been observed that the formation of magnetite was enhanced if cells of $M$. magnetotacticum were growing by dissimilatory nitrate reduction (Blakemore et al. 1985). On the basis of these observations, it was proposed by Fukumori et al. (1997) that the dissimilatory nitrite reductase of $M$. magnetotacticum could function as an $\mathrm{Fe}(\mathrm{II})$ oxidizing enzyme for magnetite synthesis under anaerobic conditions.

Frankel et al. (1983) examined the nature and distribution of major iron compounds in M. magnetotacticum by using Fe-57 Mößbauer spectroscopy. They proposed a model in which $\mathrm{Fe}(\mathrm{III})$ is taken up by the cell and reduced to $\mathrm{Fe}(\mathrm{II})$ as it enters the cell. It is then thought to be reoxidized to form a low-density hydrous $\mathrm{Fe}(\mathrm{III})$ oxide, which is then dehydrated to form a highdensity Fe(III) oxide (ferrihydrite), which can be directly observed in cells. In the last step, one-third of the Fe(III) ions in ferrihydrite are reduced and, with further dehydration, magnetite is produced. It is thought that the 
final two steps occur within the magnetosome vesicle, which acts as a further constraint on crystal growth.

\section{Molecular biology of magnetotactic bacteria}

Attempts to address the molecular biology of magnetosome formation have been hampered by several problems including the lack of a significant number of magnetotactic bacterial strains, the fastidiousness of the organisms in culture, the elaborate techniques required for the growth of these organisms and the inability of almost all these strains to grow on the surface of agar plates used to screen for mutants. Therefore, our knowledge of the genetic determination of magnetosome formation is still fragmentary.

Initial studies addressing molecular genetics in magnetotactic bacteria were made with $M$. magnetotacticum strain MS-1. It was shown that at least some of the genes of this organism can be functionally expressed in Escherichia coli and that the transcriptional and translational elements of the two microorganisms are compatible. Berson et al. (1989) were able to clone and functionally express the recA gene from $M$. magnetotacticum in $E$. coli. They then cloned a $2-\mathrm{kb}$ DNA fragment from $M$. magnetotacticum that complemented iron-uptake deficiencies in E. coli and Salmonella typhimurium mutants lacking a functional aroD gene (biosynthetic dehydroquinase). This suggests that the $2-\mathrm{kb}$ DNA fragment may have a function in iron uptake in M. magnetotacticum (Berson et al. 1991).

Matsunaga et al. (1992) attempted to establish a genetic system in Magnetospirillum strain AMB-1. Cells of this species were reported to form magnetic colonies on the surface of agar plates when grown under an incubation atmosphere containing $2 \%$ oxygen. This feature facilitated the selection of non-magnetic mutants of Magnetospirillum strain AMB-1 by Tn 5 mutagenesis by conjugal transfer. It was concluded that at least three regions of the chromosome are required for the synthesis of magnetosomes. One of these regions was found to contain a gene, designated $\operatorname{mag} A$, that encodes a protein that is homologous to cation efflux proteins, in particular the E. coli potassium-ion-translocating protein KefC (Nakamura et al. 1995a). Membrane vesicles prepared from $E$. coli cells expressing $m a g A$ took up iron when ATP was supplied, indicating that energy was required for the uptake of iron. The expression of $\operatorname{mag} A$ was enhanced when wild-type Magnetospirillum AMB-1 cells were grown under iron-limited conditions rather than iron-sufficient conditions in which they would produce more magnetosomes (Nakamura et al. 1995b). Thus, the role of the $\operatorname{mag} A$ gene in magnetosome synthesis is unclear.

Okuda et al. (1996) took a "reverse genetics" approach to the magnetosome problem. They used the $\mathrm{N}$-terminal amino acid sequence from a $22-\mathrm{kDa}$ protein specifically associated with the magnetosome membrane to clone and sequence its gene. On the basis of the amino acid sequence, the protein exhibits significant homology with a number of functionally diverse proteins belonging to the tetratricopeptide repeat family. However, the role of the protein in magnetosome synthesis has not yet been elucidated.

\section{Mass cultivation and isolation of magnetosomes}

Only a limited number of magnetotactic bacteria have been isolated in pure culture so far. Most of the isolates are poorly characterized in terms of growth conditions and physiology. Therefore, several Magnetospirillum strains have been used for the isolation of magnetosomes that can be grown microaerobically on simple media containing short organic acids as a carbon source and ferric chelates as a source of iron (Blakemore et al. 1979; Schüler and Baeuerlein 1996; Matsunaga et al. 1990). The cells have a strictly oxygen-dependent respiratory type of metabolism, but do not tolerate higher oxygen concentrations. As growth and magnetosome formation depend on microaerobic conditions, the control of a low oxygen concentration in the growth medium $(1 \%-3 \%)$ $\mathrm{O}_{2}$ is of critical importance (Blakemore et al. 1985; Schüler and Baeuerlein 1998).

$M$. magnetotacticum was the first magnetotactic bacterium available in pure culture and was used in the initial studies. One of the reasons for oxygen sensitivity in this organism may be the lack of the oxygen-protective enzyme catalase. Addition of catalase to the growth medium resulted in increased oxygen tolerance (Blakemore et al. 1979). M. gryphiswaldense and Magnetospirillum AMB-1 are more oxygen-tolerant and easier to grow on a large scale. If grown from large inocula, cultures are tolerant to atmospheric air, which obviates the need for elaborate microaerobic techniques. The maximum cell yields reported so far are $0.33 \mathrm{~g} / 1$ (dry weight) for $M$. gryphiswaldense grown in a 100-1 fermenter (Schüler and Baeuerlein 1997a) and $0.34 \mathrm{~g} / 1$ for Magnetospirillum AMB-1 grown at a 4-1 scale (Matsunaga et al. 1997).

Techniques for the isolation and purification of magnetosome particles from Magnetospirillum species are based on magnetic separation (Gorby et al. 1988; Okuda et al. 1996) or a combination of a sucrose-gradient centrifugation and a magnetic separation technique (Schüler and Baeuerlein 1997b). These procedures leave the surrounding membrane intact and magnetosome preparations are apparently free of contaminating material. Owing to the presence of the enveloping membrane, isolated magnetosome particles form stable, well-dispersed suspensions (Fig. 5). After solubilization of the membrane by a detergent, the remaining inorganic crystals tend to agglomerate as a result of magnetic attractive forces. Typically, $2.6 \mathrm{mg}$ bacterial magnetite can be derived from a 1000-ml culture of Magnetospirillum AMB-1 (Matsunaga et al. 1997), while a similar yield was reported for $M$. gryphiswaldense (Schüler and Baeuerlein 1997a). 
Fig. 5 Purified magnetosomes from $M$. gryphiswaldense. Owing to the presence of the enveloping membrane, isolated magnetosome particles form stable, well-dispersed suspensions (Bar equivalent to $100 \mathrm{~nm})$

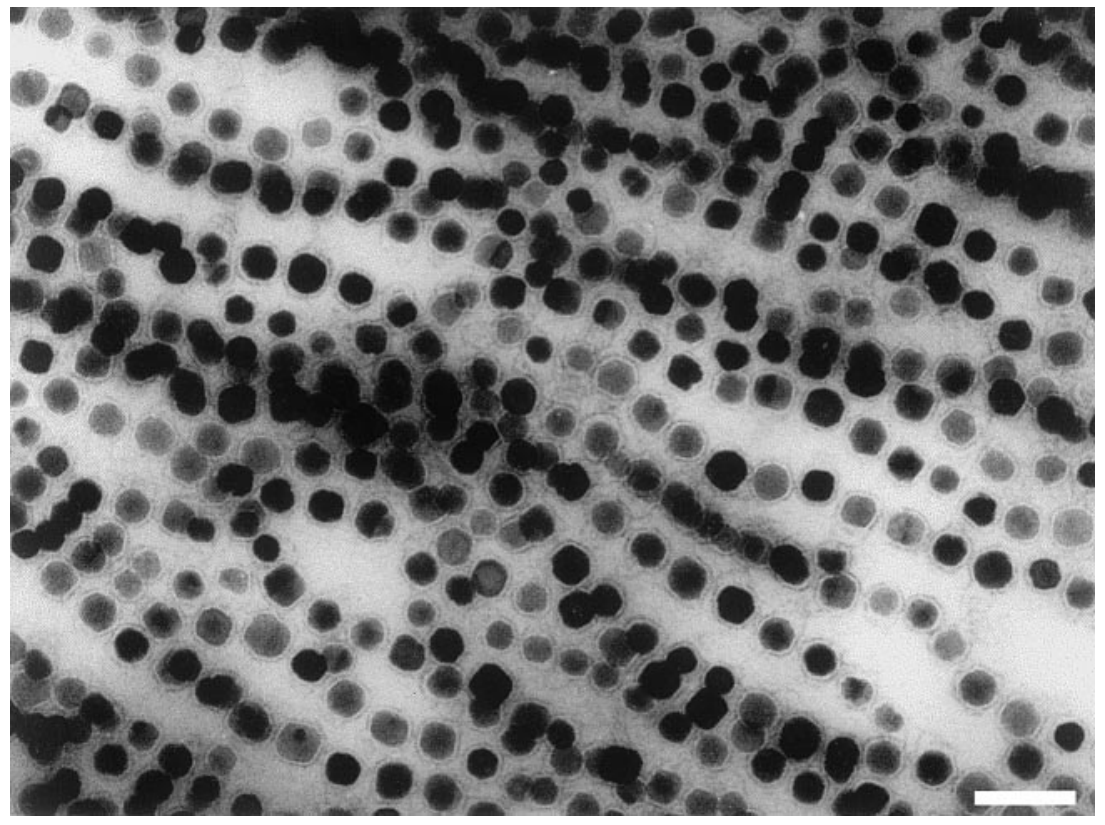

\section{Biotechnological applications}

The formation of magnetic particles within biological membranes is of great interest in terms of forming small synthetic particles under closely controlled synthesis conditions. Small magnetic particles can be formed synthetically by following various routes. However, particles formed this way are non-uniform, often not fully crystalline, compositionally nonhomogeneous, and in an agglomerated state, which imposes problems in processing (Sarikaya 1994). Therefore, their synthesis by a biological process promises advantages in terms of controlling growth and morphological properties. Moreover, biomineralization provides a way to produce highly uniform magnetite crystals without the drastic regimes of temperature, $\mathrm{pH}$ and pressure that are often needed for their industrial production (Mann et al. 1990). Soon after the discovery of magnetotactic bacteria, their biotechnological potential was realized and numerous commercial uses of the small magnetic crystals have been contemplated. Examples for the use of magnetic microorganisms generally fall into two categories, which involve either whole, living cells and their magnetotactic behavior or utilize isolated magnetosome particles.

\section{Applications of magnetic cells}

Applications based on the first category include the use of magnetotactic bacteria for the nondestructive domain analysis of soft magnetic materials. When motile magnetotactic cocci were applied to the sample surface, the bacteria oriented, migrated and accumulated in the stray fields originating from the magnetic domains, allowing visualization of the domain structure (Harasko et al. 1993, 1995). Using a similar technique, Funaki et al. (1992) employed magnetotactic bacteria to locate mag- netic poles on meteoritic magnetic grains. Bahaj et al. (1994, 1998) considered the use of magnetotactic bacteria for the removal of heavy metals and radionuclides from wastewater. High-gradient magnetic separation as well as a low-magnetic field system based on their directed motility have been used to remove metal-loaded bacteria from water. A "microbial magnetometer" was devised for the prediction of oxygen depletion in bottom sediments and overlying water, which is based on the magnetotactic and microaerophilic behavior of natural populations of magnetotactic bacteria, tracking their position and magnetic strength by a magnetic sensor (Rhoads 1995). All the examples described above rely on living, actively swimming and partially non-cultivable magnetotactic bacteria. Because of the fastidiousness and limited availability of these bacteria, practical applications remain in question.

\section{Applications of isolated magnetosome particles}

The small size of isolated magnetosome particles provides a large surface-to-volume ratio, which makes them useful as carriers for the immobilization of relatively large quantities of bioactive substances, which can then separated by magnetic fields. In initial studies, bacterial magnetosomes from non-cultivable magnetotactic bacteria were used for immobilizing the enzymes glucose oxidase and uricase as components of medically important biosensors. The glucose oxidase bound to biogenic magnetite particles had 40-fold higher activity than the same enzyme bound to artificial magnetite and Zinc ferrite particles in this study (Matsunaga and Kamyia 1987).

Magnetosomes have been also used for the generation of magnetic antibodies. Following treatment with glutaraldehyde, bacterial magnetite particles were coupled to antibodies to form conjugates. In one example, magnetic antibodies could be used for the quantification 
of IgG. The procedure involved immobilizing fluorescein-isothiocyanate-conjugated anti-(mouse $\mathrm{IgG})$ antibodies on bacterial magnetosome particles (Nakamura et al. 1991). The presence of the magnetosome membrane resulted in dispersion and handling properties superior to those of synthetic magnetic particle conjugates (Matsunga 1991). Other reported examples for the application of antibodies immobilized on bacterial magnetosomes include the detection and removal of E. coli cells from bacterial suspensions (Nakamura et al. 1993a) as well as the highly sensitive detection of allergens (Nakamura and Matsunaga 1993).

Matsunga and coworkers incorporated bacterial magnetite particles into eucaryotic cells, which could be manipulated by a magnetic field. Magnetosomes were introduced into red blood cells by fusion with bacterial spheroplasts mediated by polyethylene glycol. Whole magnetotactic bacteria have also been introduced into leukocytes by phagocytosis (Matsunaga et al. 1989).

Bacterial magnetite particles were also used as carriers for the introduction of DNA into cells. In a method described by Takeyama et al. (1995), bacterial magnetite particles coated with plasmid DNA were used for the ballistic transformation of the marine cyanobacterium Synechocystis using a particle gun. In another experiment, DNA oligonucleotides were immobilized on bacterial magnetite particles and used for the detection of mRNA (Sode et al. 1993).

Another application of bacterial magnetosomes may lie in their potential use as a contrast agent for magnetic resonance imaging and tumor-specific drug carriers based on intratumoral enrichment (Bulte and Brooks 1997). Synthetic liposomes containing superparamagnetic iron oxide particles have already been used in biomedical applications of this type (Päuser et al. 1997). Again, because of their unique magnetic and crystalline properties and the natural presence of a surrounding membrane, magnetosomes might be superior in some applications. It has also been demonstrated that applying the principle of confined biomineralization within the cavity of apoferritin resulted in the innovative material magnetoferritin, which was more effective as a magnetic-resonance contrast agent than chemosynthetic particles (Bulte et al. 1994).

\section{Perspectives}

Although the biotechnological potential of bacterial magnetite has been demonstrated, to date no application has been exploited on a commercial scale. This is partially because of the problems related to mass cultivation of magnetotactic bacteria, which is still too expensive for most practical purposes. However, the use of bacterial magnetosomes could be competitive in some specialized applications, where perfect crystalline properties and relatively small amounts are required, as in some biomedical applications, for example. Another reason for the limited practicability of many ideas is the lack of a fundamental understanding of the biochemical and genetic principles behind the process of bacterial magnetite biomineralization. More research in this field is clearly required. The most critical issue is the mechanism by which the organic matrix controls the nucleation and growth of the particles. Further investigation of the structure and composition of the magnetosome membrane and its protein organization is therefore essential for understanding ion transport through the membrane and the early stages of crystal formation.

Increased efforts should be directed to the genetic and molecular biological analysis of magnetosome formation. The application of genetic engineering techniques might possibly result in magnetosome particles with improved properties and a more dependable production process. For example, it has been suggested that magnetosome-specific proteins might be used for the construction of gene fusions to couple bioactive substances directly in order to display them on the surface of the magnetosome particles (Nakamura et al. 1995b). Genetic engineering might also be used for control of the chemical composition. The modification of the transport system responsible for the accumulation of iron into the magnetosome vesicle might result in an altered specificity for metal uptake, potentially yielding crystals with novel magnetic and crystalline properties. Once the genes for the biomineralization pathway are identified, they might be expressed in a readily cultivable host organism, thereby potentially eliminating the difficulties associated with the cultivation of magnetotactic bacteria. Functional expression of single genes from Magnetospirillum in E. coli has already been demonstrated (Berson et al. 1989, 1991), but the heterologous expression of genes related to bacterial biomineralization could be limited by the lack of an intracellular compartment. Alternatively, bacterial hosts with an existing intracytoplasmatic membrane system, such as phototrophic bacteria, might be more appropriate for expression and intracellular targeting of the biomineralization machinery.

Finally, in the light of the dramatic diversity of naturally occurring magnetotactic bacteria with variable crystal morphologies, increased effort should be given to the isolation and study of other magnetotactic species with potentially unique features of the biomineralization process. Understanding how different bacteria achieve species-specific control over the biomineralization process could be used in tailoring different crystal morphologies with the desired properties.

Acknowledgements D.S. was supported by grants from the Deutsche Forschungsgemeinschaft and the Max-Planck-Society. R.B.F. was supported by NSF grant CHE 9714101 . We are grateful to E. Baeuerlein, D.A. Bazylinski, S. Spring and B. Tebo for discussions and collaboration.

\section{References}

Bahaj AS, Croudace IW, James PAB (1994) Treatment of heavy metal contaminants using magnetotactic bacteria. IEEE Trans Magnet 30: 4707-4709 
Bahaj AS, Croudace IW, James PAB, Moeschler FD, Warwick PE (1998) Continuous radionuclide recovery from wastewater using magnetotactic bacteria. J Magnet Magnet Mater 184: 241-244

Bazylinski DA (1995) Structure and function of the bacterial magnetosome. ASM News 61: 337-343

Bazylinski DA, Frankel RB, Jannasch HW (1988) Anaerobic magnetite production by a marine magnetotactic bacterium. Nature 334: 518-519

Bazylinski DA, Garratt-Reed A, Frankel RB (1994) Electron-microscopic studies of magnetosomes in magnetotactic bacteria. Microscopy Res Tech 27: 389-401

Berson AE, Hudson DV, Waleh NS (1989) Cloning and characterization of the recA gene of Aquaspirillum magnetotacticum. Arch Microbiol 152: 567-571

Berson DA, Hudson DV, Waleh NS (1991) Cloning of a sequence of Aquaspirillum magnetotacticum that complements the aroD gene of Escherichia coli. Mol Microbiol 5: 2262-2264

Blakemore RP (1975) Magnetotactic bacteria. Science 190: 377-379

Blakemore RP (1983) Magnetic bacteria and products derived therefrom. US patent 4385119

Blakemore RP, Maratea D, Wolfe RS (1979) Isolation and pure culture of a freshwater magnetic spirillum in chemically defined medium. J Bacteriol 140: 720-729

Blakemore RP, Short KA, Bazylinski DA, Rosenblatt C, Frankel RB (1985) Microaerobic conditions are required for magnetite formation within Aquaspirillum magnetotacticum. Geomicrobiol J 4: $53-71$

Bulte JWM, Brooks RA (1997) Magnetic nanoparticles as contrast agents for imaging. In: Häfeli U, Schütt W, Teller J, Zborowski M (eds) Scientific and clinical applications of magnetic carriers. Plenum, New York, London, pp 527-543

Bulte JWM, Douglas T, Mann S, Frankel RB, Moskowitz BM, Brooks RA, Baumgartner CD, Vymazal J, Frank JA (1994) Magnetoferritin: biomineralization as novel molecular approach in the design of the iron-oxide-based magnetic resonance contrast agents. Invest Radiol 29: S214-216

Burgess JG, Kawaguchi R, Sakaguchi T, Thornhill RH, Matsunaga T (1993) Evolutionary relationships among Magnetospirillum strains inferred from phylogenetic analysis of $16 \mathrm{~S}$ rRNA sequences. J Bacteriol 175: 6689-6694

DeLong EF, Frankel RB, Bazylinski DA (1993) Multiple evolutionary origins of magnetotaxis in bacteria. Science 259: 803-806

Dunin-Borkowski RE, McCartney MR, Frankel RB, Bazylinski DA, Posfai M, Buseck PR (1998) Magnetic microstructure of magnetotactic bacteria by electron holography. Science 282 : $1868-1870$

Frankel RB, Bazylinski DA (1994) Magnetotaxis and magnetic particles in bacteria. Hyperfine Interact 90: 135-142

Frankel RB, Blakemore RP (1980) Navigational compass in magnetic bacteria. J Magnet Magnet Mater 15-18: 1562-1564

Frankel RB, Papaefthymiou GC, Blakemore RP, O'Brien W (1983) $\mathrm{Fe}_{3} \mathrm{O}_{4}$ precipitation in magnetotactic bacteria. Biochim Biophys Acta 763: 147-159

Frankel RB, Bazylinski DA, Johnson MS, Taylor BL (1997) Magneto-aerotaxis in marine coccoid bacteria. Biophys J 73 994-1000

Frankel RB, Bazylinski DA, Schüler D (1998) Biomineralization of magnetic iron minerals in magnetotactic bacteria. Supramol Sci 5: $383-390$

Fukumori Y, Oynagi H, Yoshimatsu K, Noguchi Y, Fujiwara T (1997) Enzymatic iron oxidation and reduction in magnetite synthesizing Magnetospirillum magnetotacticum. J Phys IV 7: $659-662$

Funaki M, Sakai H, Matsunaga T, Hirose S (1992) The S pole distribution on magnetic grains in pyroxenite determined by magnetotactic bacteria. Phys Earth Planet Interior 70: 253-260

Gorby YA, Beveridge TJ, Blakemore RP (1988) Characterization of the bacterial magnetosome membrane. J Bacteriol 170: 834-841

Guerin WF, Blakemore RP (1992) Redox cycling of iron supports growth and magnetite synthesis by Aquaspirillum magnetotacticum. Appl Environ Microbiol 58: 1102-1109
Guerinot ML (1994) Microbial iron transport. Annu Rev Microbiol 48: 743-772

Harasko G, Pfützner H, Rapp E, Futschik K, Schüler D (1993) Determination of the concentration of magnetotactic bacteria by means of susceptibility measurements. Jpn J Appl Phys 32: 252-260

Harasko G, Pfützner H, Futschik K (1995) Domain analysis by means of magnetotactic bacteria. IEEE Trans Magnet 31: 938949

Kirschvink JL, Kobayashi-Kirschvink A, Woodford BJ (1992) Magnetite biomineralization in the human brain. Proc Natl Acad Sci USA 89: 7683-7687

Lovley DR, Stolz JF, Nord GL, Phillips EJP (1987) Anaerobic production of magnetite by a dissimilatory-iron reducing microorganism. Nature 330: 252-254

Lowenstam HA (1981) Minerals formed by organisms. Science 211: $1126-1131$

Maher BA (1998) Magnetite biomineralization in termites. Proc R Soc Lond Biol 265: 733-737

Mann S (1993) Molecular tectonics in biomineralization and biomimetic materials chemistry. Nature 365: 499-505

Mann S, Sparks NHC, Walker MM, Kirschvink JL (1988) Ultrastructure, morpholgy and organization of biogenic magnetite from sockeye salmon, Oncorhynchus nerka: implications for magnetroreception. J Exp Biol 140: 35-49

Mann S, Sparks NHC, Board RG (1990) Magnetotactic bacteria: microbiology, biomineralization, palaeomagnetism and biotechnology. Adv Microbiol Physiol 31: 125-181

Matsunaga T (1991) Applications of bacterial magnets. Trends Biotechnol 9: 91-95

Matsunaga T, Kamiya S (1987) Use of magnetic particles isolated from magnetotactic bacteria for enzyme immobilization. Appl Microbiol Biotechnol 26: 328-332

Matsunaga T, Hashimoto K, Nakamura N, Nakamura K, Hashimoto S (1989) Phagocytosis of bacterial magnetite by leukocytes. Appl Microbiol Technol 31: 401-405

Matsunaga T, Tadokoro F, Nakamura N (1990) Mass culture of magnetic bacteria and their application to flow type immunoassays. IEEE Trans Magnet 26: 1557-1559

Matsunaga T, Nakamura C, Burgess JG, Sode S (1992) Gene transfer in magnetic bacteria: transposon mutagenesis and cloning of genomic DNA fragments required for magnetosome synthesis. J Bacteriol 174: 2748-2753

Matsunaga T, Kamiya S, Tsujimura N (1997) Production of protein (enzyme, antibody, protein A)-magnetite complex by genetically engineered magnetic bacteria Magnetospirillum sp. AMB-1. In: Häfeli U, Schütt W, Teller J, Zborowski M (eds) Scientific and clinical applications of magnetic carriers. Plenum, New York London, pp 287-294

Meldrum FC, Mann S, Heywood BR, Frankel RB, Bazylinski DA (1993a) Electron microscopy study of magnetosomes in two cultured vibroid magnetotacic bacteria. Proc R Soc Lond [Biol] 251: $237-242$

Meldrum FC, Mann S, Heywood BR, Frankel RB, Bazylinski DA (1993b) Electron microscopy study of magnetosomes in a cultured coccoid magnetotactic bacterium. Proc R Soc Lond [Biol] 251: $231-236$

Moskowitz BM (1995) Biomineralization of magnetic minerals. Rev Geophys 33: 123-128

Nakamura N, Matsunaga T (1993) Highly sensitive detection of allergen using bacterial magnetic particles. Anal Chim Acta 281: $585-589$

Nakamura N, Hashimoto K, Matsunaga T (1991) Immunoassy method for the determination of immunoglobulin $G$ using bacterial magnetic particles. Anal Chem 63: 268-272

Nakamura N, Burgess JG, Yagiuda K, Kiudo S, Sakaguchi T, Matsunaga T (1993a) Detection and removal of Escherichia coli using fluorescin isothiocyanate conjugated monoclonal antibody immobilized on bacterial magnetic particles. Anal Chem 65: 2036-2039

Nakamura C, Sakaguchi T, Kudo S, Burgess JG, Sode K, Matsunaga T (1993b) Characterization of iron uptake in the 
magnetic bacterium Aquaspirillum sp. AMB-1. Appl Biochem Biotechnol 39/40: 169-177

Nakamura C, Burgess JG, Sode K, Matsunaga T (1995a) An ironregulated gene, $\operatorname{mag} A$, encoding an iron transport protein of Magnetospirillum sp. strain AMB-1. J Biol Chem 270: 28 39228396

Nakamura C, Kikuchi T, Burgess JG, Matsunaga T (1995b) Ironregulated expression and membrane localization of the magA protein in Magnetospirillum $\mathrm{sp}$ strain AMB-1. J Biochem (Tokyo) 118: 23-27

Okuda Y, Denda K, Fukumori Y (1996) Cloning and sequencing of a gene encoding a new member of the tetratricopeptide protein family from magnetosomes of Magnetospirillum magnetotacticum. Gene 171: 99-102

Paoletti LC, Blakemore RP (1986) Hydroxamate production by Aquaspirillum magnetotacticum. J Bacteriol 167: 153-163

Päuser S, Reszka R, Wagner S, Wolf KJ, Buhr HJ, Berger G (1997) Liposome-encapsulated superparamagnetic iron oxide particles as markers in an MRI-guided search for tumor-specific drug carriers. Anticancer Drug Des 12: 125-135

Posfai M, Buseck PR, Bazylinski DA, Frankel RB (1998) Reaction sequence of iron sulfide minerals in bacteria and their use as biomarkers. Science 280: 880-883

Rhoads D (1995) Microbial magnetometer enables timely prediction of oxygen depletion in bottom sediments and overlying bottom water. Environ Bull 5: http: //www.saic.com/environ/ bulletins/spring95/index.html

Sakaguchi T, Burgess JG, Matsunaga T (1993) Magnetite formation by a sulphate-reducing bacterium. Nature 365: 47-49

Sarikaya M (1994) An introduction to biomimetics: a structural viewpoint. Microsc Res Tech 27: 360-375

Schleifer KH, Schüler D, Spring S, Weizenegger M, Amann R, Ludwig W, Köhler M (1991) The genus Magnetospirillum gen. nov., description of Magnetospirillum gryphiswaldense sp. nov. and transfer of Aquaspirillum magnetotacticum to Magnetospirillum magnetotacticum comb. nov. Syst Appl Microbiol 14: 379-385

Schüler D, Baeuerlein E (1996) Iron-limited growth and kinetics of iron uptake in Magnetospirillum gryphiswaldense. Arch Microbiol 166: 301-307

Schüler D, Baeuerlein E (1997a) Iron transport and magnetite crystal formation of the magnetic bacterium Magnetospirillum gryphiswaldense. J Phys IV 7: 647-650

Schüler D, Baeuerlein E (1997b) The biomineralization of magnetite in magnetic bacteria. In: Trautwein A (ed) Bioinorganic chemistry: transition metals in biology and coordination chemistry. Deutsche Forschungsgemeinschaft. Wiley-VCH, Weinheim New York Chichester, pp 24-36

Schüler D, Baeuerlein E (1998) Dynamics of iron uptake and $\mathrm{Fe}_{3} \mathrm{O}_{4}$ biomineralization during aerobic and microaerobic growth of Magnetospirillum gryphiswaldense. J Bacteriol 180: 159-162
Schüler D, Köhler M (1992) The isolation of a new magnetic spirillum. Zentralbl Mikrobiol 147: 150-151

Schüler D, Uhl R, Baeuerlein E (1995) A simple light-scattering method to assay magnetism in Magnetospirillum gryphiswaldense. FEMS Microbiol Lett 132: 139-145

Schüler D, Baeuerlein E, Bazylinski DA (1997) Localization and occurrence of magnetosome proteins from Magnetospirillum gryphiswaldense studied by an immunological method. In: Abstracts of the 97th General Meeting of the American Society for Microbiology, Miami, p 332

Schwartz BB, Blakemore N (1984) Magnetotactic bacteria in clinical assay, immunoassy and cells separation procedures and the like. US patent 4677067

Sode K, Kudo S, Sakaguchi T, Nakamura N, Matsunaga T (1993) Application of bacterial magnetic particles for highly selective messenger-RNA recovery system. Biotechnol Tech 7: 688-694

Sparks NHC, Mann S, Bazylinski D, Lovley D, Jannasch HW, Frankel RB (1990) Structure and morphology of magnetite anaerobically-produced by a marine magnetotactic bacterium and a dissimilatory iron-reducing bacterium. Earth Planet Sci Lett 98: 14-22

Spring S, Schleifer KH (1995) Diversity of magnetotactic bacteria. System Appl Microbiol 18: 147-153

Spring S, Amann R, Ludwig W, Schleifer KH, Gemerden Hv, Petersen N (1993) Dominating role of an unusual magnetotactic bacterium in the microaerobic zone of a freshwater sediment. Appl Environ Microbiol 59: 2397-2403

Stolz JF (1993) Magnetosomes. J Gen Microbiol 139: 1663-1670

Takeyama H, Yamazawa A, Nakamura C, Matsunaga T (1995) Application of bacterial magnetic particles as novel DNA carriers for ballistic transformation of a marine cyanobacterium. Biotechnol Tech 9: 355-360

Tamegai H, Fukumori Y (1994) Purification and some molecular and enzymatic features of a novel ccb-type cytochrome c oxidase from a microaerobic denitrifier, Magnetospirillum magnetotacticum. FEBS Lett 347: 22-26

Tamegai H, Yamanaka T, Fukumori Y (1993) Purification and properties of a "cytochrom $a_{1}^{\prime}$-like hemoprotein from a magnetotactic bacterium, Aquaspirillum magnetotacticum. Biochim Biophys Acta 1158: 137-243

Torres de Araujo FF, Pires MA, Frankel RB, Bicudo CEM (1986) Magnetite and magnetotaxis in algae. Biophys J 50: 375-378

Wiltschko R, Wiltschko W (1995) Magnetic orientation in animals. Springer, Berlin Heidelberg New York

Yamazaki T, Oyanagi H, Fujiwara T, Fukumori Y (1995) Nitrite reductase from the magnetotactic bacterium Magnetospirillum magnetotacticum - a novel cytochrome-cd(1) with Fe(II)-nitrite oxidoreductase activity. Eur J Biochem 233: 665-671 